\title{
ERNICA guidelines for the management of rectosigmoid Hirschsprung's disease
}

\author{
Kristiina Kyrklund ${ }^{1 *}$, Cornelius E. J. Sloots ${ }^{2}$, Ivo de Blaauw ${ }^{3}$, Kristin Bjørnland ${ }^{4}$, Udo Rolle ${ }^{5}$, Duccio Cavalieri ${ }^{6}$, \\ Paola Francalanci ${ }^{7}$, Fabio Fusaro ${ }^{8}$, Annette Lemli ${ }^{9}$, Nicole Schwarzer ${ }^{9}$, Francesco Fascetti-Leon ${ }^{10}$, Nikhil Thapar ${ }^{11}$, \\ Lars Søndergaard Johansen ${ }^{12}$, Dominique Berrebi ${ }^{13}$, Jean-Pierre Hugot ${ }^{14}$, Célia Crétolle ${ }^{15}$, Alice S. Brooks ${ }^{16}$, \\ Robert M. Hofstra ${ }^{16}$, Tomas Wester $^{17}$ and Mikko P. Pakarinen ${ }^{1}$
}

\begin{abstract}
Background: Hirschsprung's disease (HSCR) is a serious congenital bowel disorder with a prevalence of 1/5000. Currently, there is a lack of systematically developed guidelines to assist clinical decision-making regarding diagnostics and management.

Aims: This guideline aims to cover the diagnostics and management of rectosigmoid HSCR up to adulthood. It aims to describe the preferred approach of ERNICA, the European Reference Network for rare inherited and congenital digestive disorders.

Methods: Recommendations within key topics covering the care pathway for rectosigmoid HSCR were developed by an international workgroup of experts from 8 European countries within ERNICA European Reference Network from the disciplines of surgery, medicine, histopathology, microbiology, genetics, and patient organization representatives. Recommendation statements were based on a comprehensive review of the available literature and expert consensus. AGREE II and GRADE approaches were used during development. Evidence levels and levels of agreement are noted.
\end{abstract}

Results: Thirty-three statements within 9 key areas were generated. Most recommendations were based on expert opinion.

Conclusion: In rare or low-prevalence diseases such as HSCR, there remains limited availability of high-quality clinical evidence. Consensus-based guidelines for care are presented.

Keywords: Rectosigmoid Hirschsprung's disease, HSCR, Diagnosis, Management, Follow-up

\section{Background}

Hirschprung's disease (HSCR) is a congenital intestinal motility disorder with an incidence of 1:5000, with a male to female predominance of $4: 1$. It is characterized by an absence of enteric ganglion cells from the distal intestine, causing chronic functional bowel obstruction [1]. Although HSCR can affect any length of bowel from the anus proximally, $80-85 \%$ of cases are limited to the rectosigmoid

\footnotetext{
* Correspondence: kristiina.kyrklund@hus.fi

'Department of Pediatric Surgery, Children's Hospital, University of Helsinki and Helsinki University Hospital, Helsinki, Finland

Full list of author information is available at the end of the article
}

colon [2]. Operative management involves resection of the abnormally innervated bowel. Despite surgical treatment, postoperative defects in bowel function are common, and highly specialist long-term aftercare that includes transition to adult care providers is required. Currently, there is a lack of systematically developed guidelines to assist clinical decision-making in HSCR, although standardization of diagnostics, treatments and care pathways would clearly benefit patients.

Addressing healthcare inequalities and ensuring delivery of high-quality care for patients with rare or lowprevalence, complex diseases has been identified as an 
important target at the level of the European Union (EU) [3]. To address the geographical scattering of expert healthcare providers and patients, European Reference Networks (ERNs) for were founded. These currently comprise 24 ERNs from over 900 highly specialized healthcare units and 313 hospitals [3]. ERNICA is the ERN for rare inherited and congenital digestive disorders, including Hirschsprung's disease. This document aims to describe the preferred approach of ERNICA for the diagnostics and management of rectosigmoid HSCR up to adulthood. A core aim of ERNICA is to improve the quality of care that patients receive, and to reduce the long-term impact of HSCR for patients [3].

\section{Results}

\section{Recommendations for the diagnosis of HSCR (Table 1)}

Around $90 \%$ of patients with HSCR present during the neonatal period [4]. In rectosigmoid HSCR, there is a male predominance of 4:1 [5]. The classic clinical symptoms include abdominal distension (>90\%), vomiting (> $85 \%$ ), which may be bilious, and failure to pass meconium during the first $24 \mathrm{~h}$ of life (>60\%) [4]. Digital rectal examination or passage of a rectal tube typically results in the evacuation of gas and faeces, which may be explosive and/or foul-smelling. Plain abdominal $\mathrm{x}$-ray findings include dilated gas-filled loops of bowel suggestive of a distal obstruction. Some patients may have symptoms of enterocolitis at presentation. A family history of HSCR or presence of a syndrome associated with HSCR lowers the threshold for investigation. According to a recent systematic review, only $5 \%$ of 4127 infants diagnosed with HSCR between 1964 and 2013 were premature ( $<37$ weeks's gestation), but this proportion was higher (14\%) amongst patients born during recent years [6]. Contemporary studies suggest that late presentation beyond 3 years of age is unusual $[4,7]$.

Representative rectal histology is required for the diagnosis of HSCR. Rectal biopsies may be taken as suction or open surgical biopsies, opting for the least invasive, feasible method. Biopsies should be taken a minimum of $2 \mathrm{~cm}$ above the dentate line to avoid the physiologic aganglionic/hypoganglionic zone of the distal rectum [8]. The International Working Group of the 2009 World Congress of Gastroenterology advocates that a biopsy specimen should be at least $3 \mathrm{~mm}$ diameter, and a minimum of one-third of the sample should comprise submucosa $[9,10]$. Hematoxylin-eosin (H\&E) staining and Acetylcholine-Esterase (AChE) histochemistry are widely used. The presence of any number of ganglion cells on H\&E staining excludes HSCR. However, H\&E has

Table 1 Recommendations for the diagnosis of HSCR

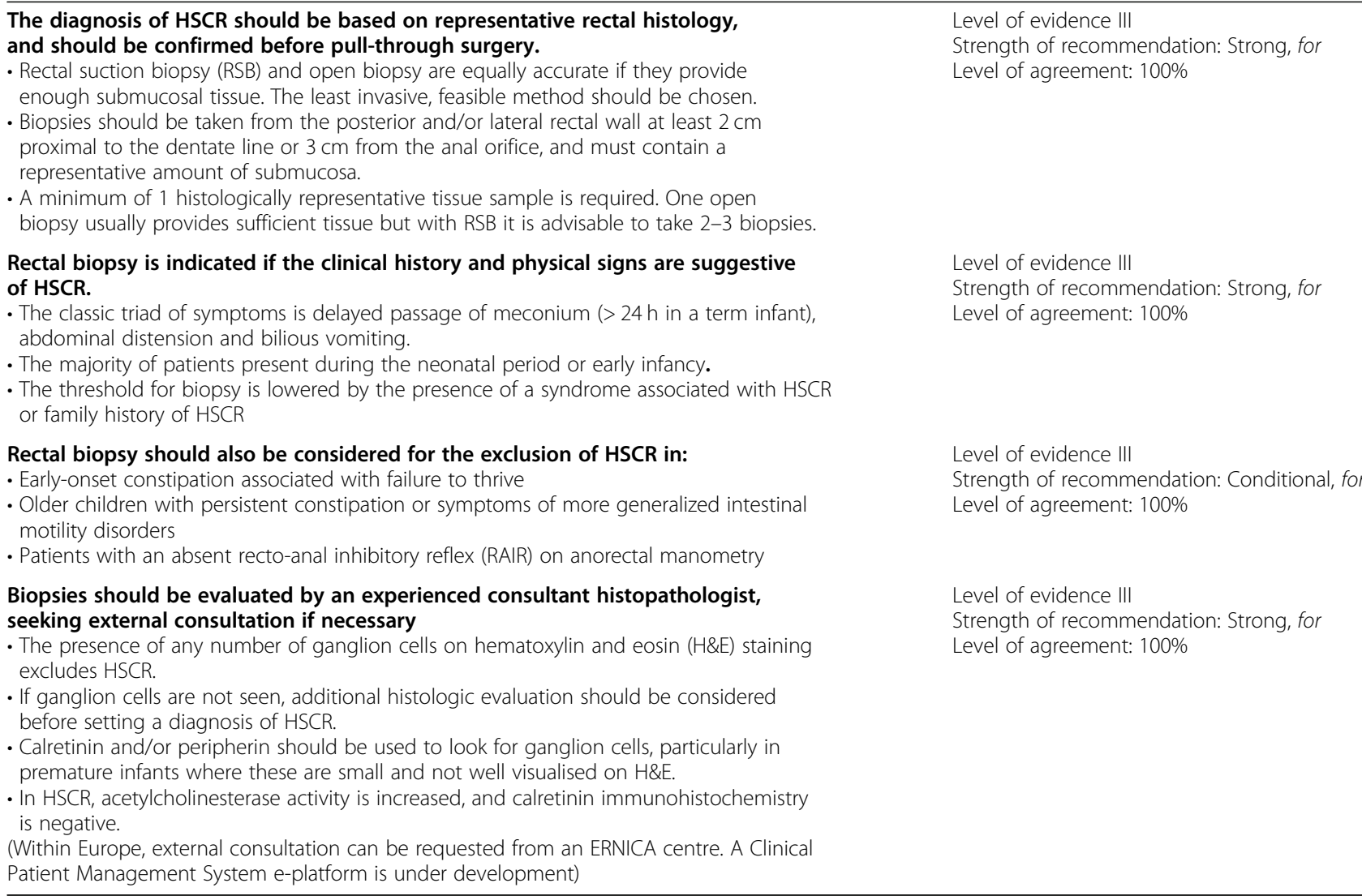


limitations for the visualisation of ganglion cells, particularly in neonates and premature babies, where these may be small and immature. If ganglion cells are not seen, additional staining with calretinin and/or peripherin immunohistochemistry is advisable before setting the diagnosis of HSCR [11, 12]. Increased AChE expression is associated with the hypertrophied extrinsic nerve fibres of the aganglionic segment in most patients with HSCR [13]. With $\mathrm{AChE}$, false negatives are primarily related to age, and absence of an AChE reaction does not reliably exclude HSCR in very young neonates $[13,14]$. The sensitivity and specificity of other methods, including anorectal manometry and contrast enema are inferior to those of an adequate rectal biopsy, particularly in young infants $[15,16]$. The histopathologic assessment of HSCR is demanding, as it remains centered around demonstrating an absence of ganglion cells [8]. Careful evaluation by an experienced consultant histopathologist is necessary, using a combination of staining techniques whenever possible. External consultation is recommended in unclear cases.

\section{Recommendations for who should operate on patients with HSCR (Table 2)}

The ERNICA recommendations for centres performing pull-through surgery for HSCR are in accordance with recent European recommendations concerning the management of patients with rare diseases [17]. There is reliable evidence that performing the definitive surgical management of rare pediatric neonatal surgical conditions in specialist units improves treatment outcomes and safety for several reasons [18-20]. The concentration of care in cases with an otherwise low prevalence permits care based on sufficient cumulative experience of the indications for surgery, surgical procedures, perioperative management and post-operative follow-up [21]. The presence of allied medical specialists, including neonatal intensivists, nurses, and out-of-hours emergency services with experience in the condition also improves the "rescue phenomenon," which refers to the ability to prevent minor postoperative events from escalating into severe complications and mortality $[21,22]$. At index centers, the need for re-do pull-through operations is low, with mostly good to normal long-term continence outcomes in rectosigmoid HSCR [2, 23, 24]. From economic and policy-planning standpoints, the prevention of severe complications is also the most important determinant of the cost-effectiveness of care [25].

On a national level, favouring the feasibility of organized care networks for HSCR is the finding that patients are willing to travel long distances in order to even marginally reduce their risk of complications and death, and for better access to multidisciplinary services [21, 26]. Registries of care volumes, outcomes, cost of care and service infrastructure are necessary to enable patients, healthcare professionals and policy-makers to make informed decisions regarding the choice of care provider. Having at least two pediatric colorectal surgeons within units assists to ensure the availability of a year-round surgical service for HSCR, and the option of two-consultant operating in complex cases. Commitment to training surgeons

Table 2 Recommendations for who should operate on patients with HSCR

\begin{tabular}{ll}
\hline Patients with HSCR should undergo pull-through surgery in centres with at least & Level of evidence III \\
two pediatric colorectal surgeons and pathological, radiological and anesthetic & Strength of recommendation: Strong, for \\
expertise, including pediatric and neonatal intensive care and specialized nursing 24/7. & Level of agreement: 100\% \\
- Concentration of interdisciplinary experience is associated with better outcomes in & \\
complex or rare pediatric surgical conditions. & \\
- Accurate primary assessment of the disease phenotype in HSCR permits appropriate & Level of evidence III \\
surgical management & Strength of recommendation: Strong, for \\
- The need for re-do surgery is low in centres that regularly manage HSCR and complications & Level of agreement: 100\% \\
are appropriately identified and managed & \\
Centres performing pull-through surgery for HSCR should have the capabilities to & Level of evidence III \\
manage the entire care pathway & Strength of recommendation: Strong, for \\
- This includes management of surgical complications and primary surgical management & Level of agreement: 100\% \\
of all forms of HSCR, provision of multidisciplinary care until adulthood, and & \\
specialist nursing & \\
- Ability to deliver comprehensive follow-up until adulthood, including provision of & \\
transition of care & \\
Centres that operate on HSCR patients should demonstrate active involvement & \\
in quality control and improvement & \\
- Maintaining prospective registries permits assessment and monitoring case volumes & \\
and outcomes & \\
- Commitment to training surgeons, pathologists and nurse practitioners in diagnostics & \\
and management of HSCR ensures continuity of local expertise & \\
- Up-to-date care practices and understanding of the disease process through networking & \\
and participation in continued medical and surgical education & \\
- Information should be given about the availability of patient support organizations as & \\
early as possible, and patients should be informed about the availability of current guidelines & \\
\hline
\end{tabular}


and other allied specialists ensures long-term service continuity.

Centres performing pull-through surgery for HSCR should have the capacity to manage all levels of HSCR, as aganglionosis extending proximal to the rectosigmoid affects $15-20 \%$ of patients [23]. Despite an optimal pullthrough, impairment of bowel function and enterocolitis are common during the first few years after surgery, and between 4 and $30 \%$ of patients have an associated developmental disorder or syndrome [23, 27, 28]. Competence in the management of HSCR is therefore not only defined by an ability to perform complex surgery or hospital volumes alone, but also on capacity to manage the disease process as a whole and to provide individualized long-term followup into adulthood [21]. For this, a properly functioning multidisciplinary approach is essential [21]. Evidence of quality should be based on outcome registries, alongside regular participation in internal and external assessment of benchmarks. Involvement in research is beneficial for generating knowledge regarding the effects of current and competitive therapies, which are needed to develop practices towards new standards.

\section{Recommendations for preoperative care (Table 3)}

Whilst awaiting the results of the rectal biopsy, saline rectal irrigations should be commenced to overcome the functional bowel obstruction and to enable enteral feeding. Parents can be trained to continue them at home on a daily basis until the pull-through operation. Rectal irrigations with physiological saline are performed with a soft rectal tube one to three times a day. Rectal irrigations provide effective bowel decompression in approximately $75 \%$ of HSCR patients. Patients in whom rectal irrigations fail often turn out to have long- or extended segment aganglianosis [2]. In these cases or if there is enterocolitis unresponsive to non-operative treatment, or intestinal perforation, a diverting enterostomy is indicated [29]. The safest empiric level is the distal ileum, based on the likelihood that aganglionosis will be confined distally to the colon. Whenever possible, frozen section biopsies at the planned stoma site should be obtained to confirm the presence of ganglion cells. A circumferential full thickness 'doughnut' biopsy from the site of bowel transection is most informative regarding the ganglion status at that level [29]. Additional fullthickness or seromuscular mapping biopsies may be obtained during the same operation to define the exact level of the histologic transition zone for planning the definitive pull-through surgery [30].

In a recent European survey, 96\% of responders performed a pre-operative contrast enema to guide on the likely level of aganglionosis [31]. Although a contrast enema is not considered sufficient on its own for the diagnosis of HSCR, a distinct calibre change from proximally dilated to distal constantly narrow colon suggests a transition zone at this level. The most demonstrative images are often obtained just after evacuation of the contrast material. If a contrast enema examination fails to suggest a clear transition zone in the recto-sigmoid colon, the possibility of long-segment aganglionosis and additional mapping biopsies should be considered [30].

In adult colorectal surgery, administration of a single preoperative dose of antibiotics has been shown to reduce postoperative wound infections by $75 \%$ [32]. A

Table 3 Recommendations for preoperative care in HSCR

\begin{tabular}{|c|c|}
\hline $\begin{array}{l}\text { Patients should receive saline rectal irrigations } 1-3 \text { times per day to decompress } \\
\text { the bowel until the definitive pull-through operation } \\
\text { - An additional colonic wash-out may be given for pre-operative bowel preparation } \\
\text { - See below, if there is an inadequate response to rectal irrigations }\end{array}$ & $\begin{array}{l}\text { Level of evidence III } \\
\text { Strength of recommendation: Strong, for } \\
\text { Level of agreement: } 100 \%\end{array}$ \\
\hline $\begin{array}{l}\text { A stoma is indicated if rectal irrigations do not sufficiently decompress the bowel, } \\
\text { or there are complications such as enterocolitis unresponsive to non-operative } \\
\text { treatment, or bowel perforation. } \\
\text { - The safest empiric level is an ileostomy } \\
\text { - In pneumoperitoneum, also an ileostomy provided it is proximal to the site of perforation } \\
\text { - A representative circumferential 'doughnut' biopsy taken from the site of stoma formation } \\
\text { is informative regarding the ganglionic status of the bowel at that level }\end{array}$ & $\begin{array}{l}\text { Level of evidence III } \\
\text { Strength of recommendation: Strong, for } \\
\text { Level of agreement: } 100 \%\end{array}$ \\
\hline $\begin{array}{l}\text { When possible, a pre-operative contrast enema is recommended to guide on the } \\
\text { likely level of aganglianosis } \\
\text { - A colonic caliber change suggests a histological transition zone at this level. } \\
\text { - Proximal to the rectosigmoid junction, colonic caliber changes are less accurate in predicting } \\
\text { the disease level, and the possibility of long-segment HSCR should be considered } \\
\text { - Contrast studies are complementary tools during the pre-operative workup. They do not } \\
\text { replace the need for histological assessment to confirm the diagnosis. }\end{array}$ & $\begin{array}{l}\text { Level of evidence III } \\
\text { Strength of recommendation: Conditional, for } \\
\text { Level of agreement: } 100 \%\end{array}$ \\
\hline $\begin{array}{l}\text { At pull-through surgery, one dose of broad-spectrum intravenous antibiotics should } \\
\text { be given preoperatively. } \\
\text { - The choice of antibiotics is determined by local regimens and regional resistance profiles, but } \\
\text { should include coverage of both aerobic and anaerobic bacteria } \\
\text { - No additional benefit has been shown for giving more than one pre-operative dose, but } \\
\text { antibiotics may be continued for } 24-48 \text { h post-operatively }\end{array}$ & $\begin{array}{l}\text { Level of evidence II-III } \\
\text { Strength of recommendation: Strong, for } \\
\text { Level of agreement: } 100 \%\end{array}$ \\
\hline
\end{tabular}


combination of aerobic and anaerobic bacteria coverage with a single agent or combination therapy is most effective, the choice depending on local resistance patterns. Administration of prolonged antibiotic prophylaxis has not been proven to be more effective in preventing surgical wound infections [33]. It is unknown to what extent this reduces sequelae from anastomotic leakage, deep surgical infections, urinary tract or respiratory infections [32]. Studies of antibiotic prophylaxis in the pediatric surgical population are scarce and do not include the latest techniques for HSCR surgery using minimally invasive or transanal approaches [33].

\section{Recommendations for operative management of rectosigmoid HSCR (Table 4)}

Endorectal pull-through (ERP) and Duhamel pull-through are the most common definitive operations for HSCR [31, 34]. Both ERP and Duhamel can be performed laparoscopyor laparotomy assisted, although ERP can also be performed entirely transanally in rectosigmoid HSCR [35-38]. Currently, there is no evidence to favor superiority of one technique over another in terms of surgical complications or long-term bowel functional outcomes [39-43]. Pullthrough surgery is usually performed electively within $2-3$ months after diagnosis and when the infant is stable, growing well and the bowel has been decompressed. No specific advantages have been identified for performing pullthrough surgery during the immediate neonatal period. However, there remains insufficient data for establishing the optimal timing of pull-through surgery.

Based on case series, it remains debated whether laparoscopy- or laparotomy assisted ERP results in less stretching of the anal sphincters than a totally transanally performed ERP $[28,44,45]$. In Duhamel operation, no difference in bowel functional outcomes between laparoscopic and open approaches has been shown [38, 46]. There are also no data regarding the optimal length of the Duhamel pouch, and if modifications of the retrorectal anastomosis reduce the need for spur divisions [38]. Although the Duhamel operation leaves a distal segment of aganglionic bowel anteriorly, it causes very little anal stretching and affords good visibility during surgery. A totally transanal ERP, on the other hand, confers excellent cosmesis [46]. The original transanal ERP described a long muscular rectal cuff that was split [4750]. Later reports showed equally good results with a short muscle cuff without splitting, and no cuff with full-thickness plane dissection [44, 48, 51-53]. Based on current understanding, long seromuscular cuffs should be avoided as they are associated with obstruction, constipation, and enterocolitis [46]. Preserving the integrity of the anal canal is a key goal during the operative management of all forms of HSCR. The mucosa above the dentate line contains the nerve endings responsible for the reflex arc in sensation and fecal continence, including the sampling reflex. In ERP, transanal dissection is commenced $0.5-2 \mathrm{~cm}$ proximal to the dentate line and in the Duhamel operation the posterior incision is performed $0,5-1 \mathrm{~cm}$ above it $[47,49,51,54]$.

No definite pull-through surgery should be performed without first establishing that normal ganglion cells are present in the bowel brought down to the anal canal for anastomosis. During surgery, frozen sections are a valid means for determining the presence of ganglion cells.

Table 4 Recommendations for operative management of rectosigmoid HSCR

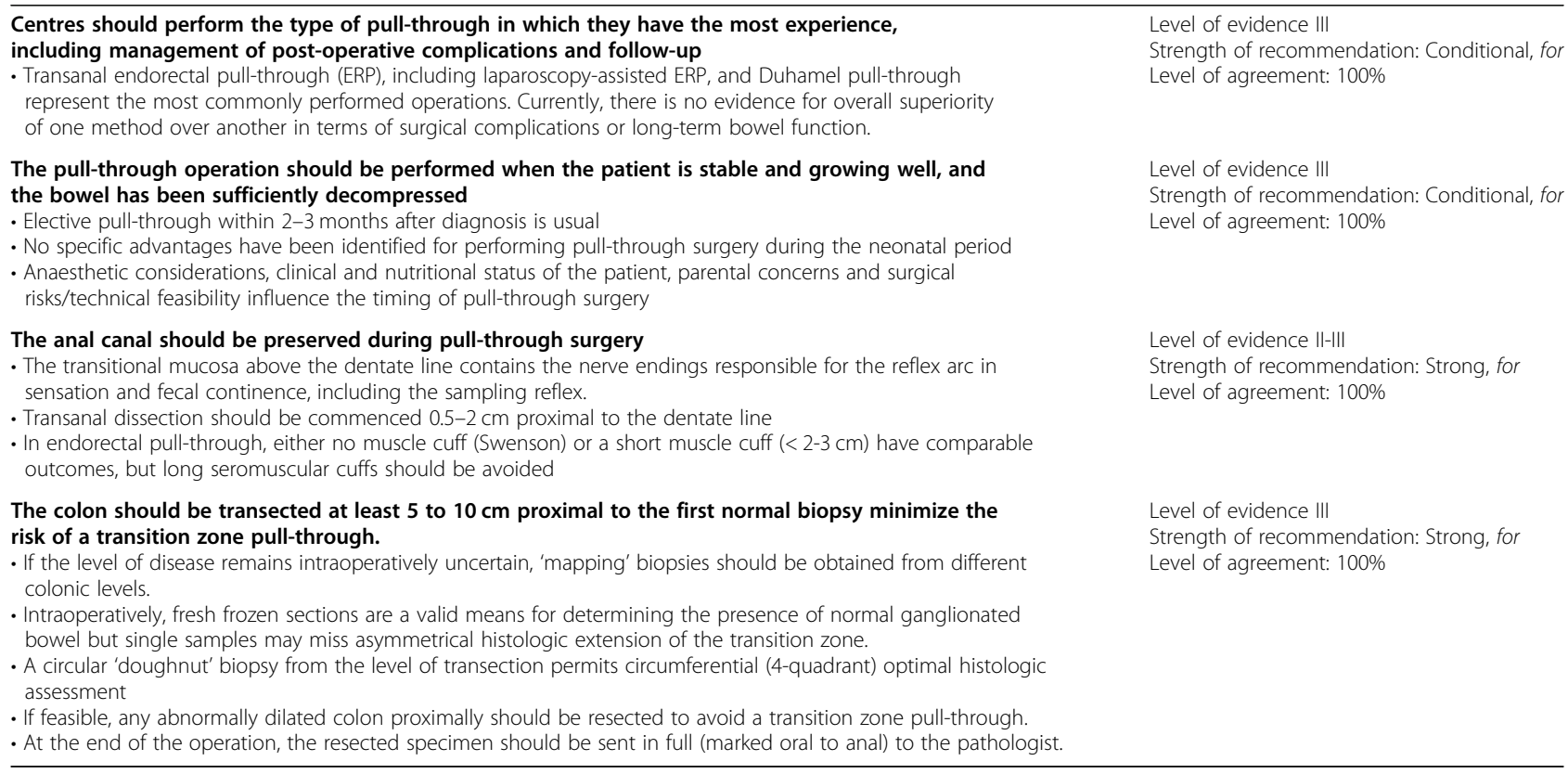


Full-thickness biopsies permit examination of both the myenteric and submucosal plexuses and thereby minimize the chance of anastomosing abnormally innervated bowel to the anal canal. Seromuscular biopsies have a lower risk of fecal spillage and postoperative perforations, but may be more prone to sampling errors if the transition zone is irregular due to a lack of full submucosal assessment [46]. As the length of the transition zone may be variable, the proximal transection margin should be a minimum of 5$10 \mathrm{~cm}$ orally to where normal ganglion cells are found, unless a "doughnut" biopsy, showing ganglion cells circumferentially in both the submucosal and myenteric plexus is available intraoperatively [55].

\section{Recommendations for early postoperative management after pull-through surgery (Table 5)}

Enhanced recovery after surgery (ERAS) protocols, which have improved outcomes in adult surgical populations were recently adapted for children undergoing elective colorectal surgery [56]. ERAS aims to optimize care in major surgical procedures through maintenance of physiologic homeostasis and by minimizing the effects of surgical stress. In children undergoing colorectal surgery, the median the time to regular diet, requirement for narcotic analgesia requirement and length of hospital stay were significantly reduced [56]. General tenets of ERAS include avoidance of prolonged fasting, use of minimally invasive surgical techniques, opioid-sparing analgesia, early reinstitution of enteral nutrition and judicious use of drains and catheters [56]. A critical feature involves engagement of the patient and carers at all phases of care. This is conducted by creating clear goals, establishing management plans for pain and nutrition, and defining the criteria for discharge to facilitate an optimal surgical experience [57].
Perianal rash or skin excoriation is common after pullthrough surgery, particularly among children who have had a stoma before the pull-through, long segment colonic or total colonic aganglionosis, and patients who have undergone surgery as neonates [58]. Preventive strategies involve active perineal nursing and the use of barrier ointments such as petroleum jelly, zinc-ointment, or other protective non-irritant creams. Topical antimicrobials may be also required if bacterial or fungal infection occurs.

Anastomotic strictures are a potential complication in colorectal surgery when there is a low circular anastomosis, as in ERP. Risk factors include ischemia, anastomotic leakage, and anastomotic tension. Anastomotic strictures may be less frequent after Duhamel procedure than ERP, where the reported occurrence is up to $10.6 \%$ (range: 0-18.9\%) [59]. Calibration of the coloanal anastomosis at least once is advisable at around 2-3 weeks after pull-through surgery; Hegar size 12 is appropriate for infants from term up to 6 months of age. Some surgeons within ERNICA performed calibration checks infrequently during follow-up, whereas others felt that a single calibration was sufficient. There is no evidence to suggest that routine anal dilatation programs after pull-through surgery prevent strictures or enterocolitis [60,61]. For an anastomotic stricture, a course of gentle once or twice daily anal dilatations may be attempted, however maintaining a low threshold for examination and dilatation under anesthesia.

\section{Recommendations for long-term follow-up (Table 6)}

Structured follow-up to adulthood, including transition of care is indicated in HSCR [62-66]. As bowel dysfunction is most common during the first few years after surgery [23], patients should be monitored more closely for the early detection of problems, including defective

Table 5 Recommendations for early postoperative management after pull-through surgery

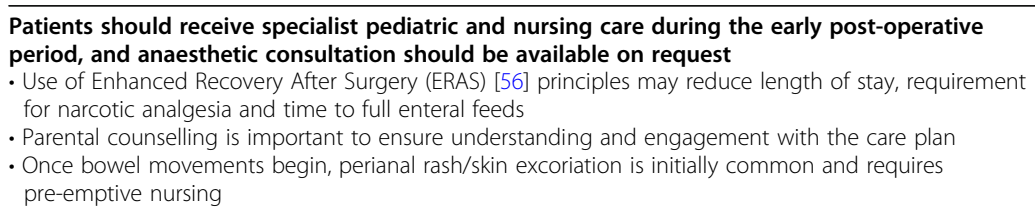

Enteral feeding can be started gradually when the patient has recovered from anaesthesia and is clinically stable

- Within $24-48 \mathrm{~h}$ in most cases

- Advance feeds as tolerated to normal diet

- There is no evidence to suggest prolonged nil by mouth periods or prevent anastomotic complications

The urinary catheter should be removed as soon as normal micturition is expected after pelvic floor surgery

- Epidural anaesthesia post-operatively is an indication for keeping a urinary catheter

- Urinary retention after removal can occur following anaesthesia or post-operative tissue swelling in the pelvic floor, and adequacy of urine output should initially be monitored.

The coloanal anastomosis should be calibrated around 2-3 weeks after pull-through surgery

- Hegar size 12 is appropriate for infants from term up to 6 months of age

- Routine serial dilatations have not been shown to reduce the prevalence of enterocolitis or late anastomotic strictures.

- If an anastomotic stricture is found, a course of gentle serial dilatations may be attempted, however with a low

threshold for examination and dilatation under anaesthesia
Level of evidence III

Strength of recommendation: Conditional, for Level of agreement: 100\%

Level of evidence III

Strength of recommendation: Conditional, for Level of agreement: 100\%

Level of evidence III

Strength of recommendation: Conditional, for Level of agreement: 100\%

Level of evidence III

Strength of recommendation: Conditional, for Level of agreement: 100\% 
Table 6 Recommendations for long-term follow-up

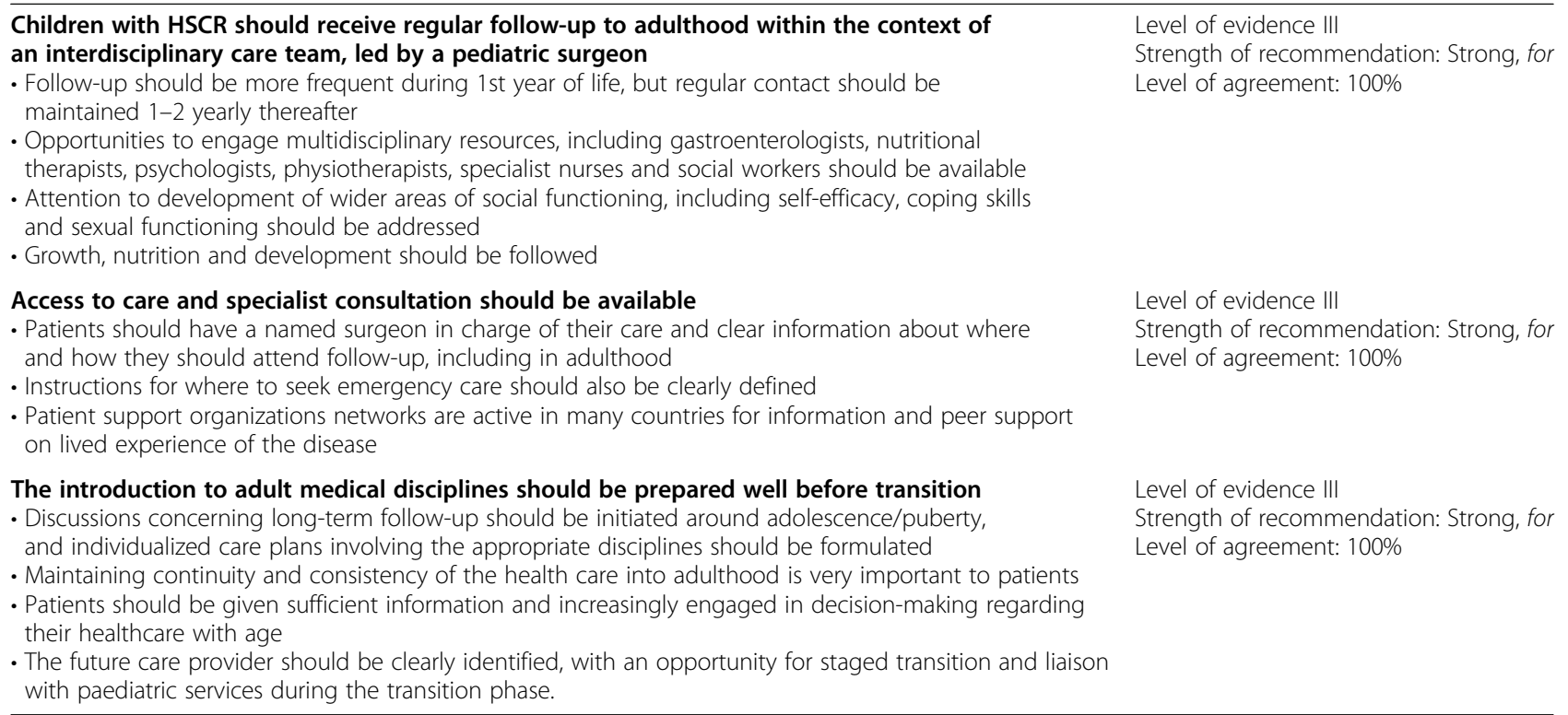

continence, enterocolitis and late complications. Clinical follow-up should be maintained even if patients are doing well. Among patients with HSCR and a syndrome associated with cognitive impairment, reaching continence is often significantly delayed. In patients with poor functional outcomes, adequate follow-up permits the institution of interventions before school age. This is important to prevent social discrimination, and to allow participation in normal childhood activities with minimal limitations from the condition [62]. As HSCR is a rare disorder in general practice, patients should also be managed by specialized medical personnel familiar with the disease [67], and receive instructions on whom to contact and where to seek medical attention in both elective and emergency circumstances. The availability of specialist nurses improves communication and access to care, and may reduce hospitalizations/admissions and health care costs [68].

In patients with HSCR, life events that necessitate follow-up include puberty and sexual development, procreation and heritability, and transition to adulthood and adult care $[64,69,70]$. Psychological factors to be addressed include self-efficacy, social functioning and coping skills for residual symptoms [71, 72]. As the parents of chronically ill children also experience considerable stress, strategies to reduce psychological morbidity that also involve the parents are likely to be beneficial [62] Achieving optimal outcomes requires collaboration between medical specialists, nurses and auxiliary resources, including psychologists and sexual therapists, physical and nutritional therapists. In addition to pediatric surgeons and gastroenterologists, urologic, gynecologic and genetic consultation should be sought as appropriate. Active involvement of the patient/family at all stages of follow-up is important to enable understanding the care plan, and to establish mutually agreed priorities for care [73]. For peer support on lived experience of the disease, patient support organizations encourage contact from patients and their families for advice and networking.

During the care pathway, as capacity for understanding increases, patients should be encouraged to acquire health literacy skills and gradually assume responsibility for their own care. Adequate information provision is important in this regard, so that including issues relating to sexual health during adulthood can be addressed [62]. Planning transition of care should commence sufficiently early, around 13-14 years of age to allow sufficient time for adjustment and should have sufficient flexibility to allow overlap and contact between the existing and future practitioners until patients are satisfactorily established in adult care [74].

\section{Recommendations for Hirschsprung's-associated enterocolitis (HAEC; Table 7)}

HAEC is the most frequent serious complication after pull-through surgery for Hirschsprung disease. Predisposing factors include family history of HSCR, long segment disease, Down syndrome (trisomy 21) and previous episodes of HAEC [75]. Approximately 30\% of HSCR patients have at least one episode of postoperative HAEC. Although the definition remains imprecise, using the Pastor et al. HAEC score items (Table 8) [76], with a cut-off of $\geq 4$ points to identify suspected HAEC is more sensitive and may have better clinical applicability [75] than Pastor and co-workers' original cut-off of $\geq 10$ points. HAEC should be suspected in the presence of diarrhea with explosive, foul-smelling or bloody stool, 
and/or fever. Patients with explosive diarrhea and decreased peripheral perfusion, lethargy, and/or, dilated loops of bowel on abdominal radiographs have severe HAEC and should be admitted [75].

Management with rectal irrigations and close observation at home with a low threshold for oral metronidazole may be an option for carefully selected, clinically well patients with mild symptoms and normal fluid balance. Differentiation from simple viral gastroenteritis may be difficult. Patients with severe HAEC should receive rectal washouts, intravenous fluid resuscitation and intravenous broad-spectrum antibiotics in hospital. Consultation of a specialist paediatric colorectal surgeon on admission, and follow-up after admission is strongly recommended.
Antibiotics may be changed to oral metronidazole when sufficient clinical improvement occurs, and rectal washouts 2-3 times per day should be performed until the child is well enough for discharge. Rectal washouts should be continued at home in cases of recurrent HAEC [77]. In recurrent or persistent HAEC accompanied by symptoms of outlet obstruction (defecation difficulties, requiring assistance with e.g. a rectal tube to pass motions), mechanical obstruction or residual aganglionosis should be ruled out [78]. Contrast enemas should not be performed during an acute episode owing to the risk of perforation [79].

Intrasphincteric botulinum toxin injections [80-82] reduce the incidence of HAEC or symptoms of outlet obstruction in $62-89 \%$ of HSCR patients after the first

Table 7 Recommendations for Hirschsprung's-associated enterocolitis (HAEC)

\author{
HAEC should be clinically suspected in the presence of diarrhoea with explosive, foul-smelling \\ stool, and/or $>4$ points from the Pastor et al. HAEC score items (Table 8) [76] \\ - The definition of HAEC remains imprecise even based on current understanding \\ - A cut-off of $>10$ points has a reported sensitivity of $42 \%$ and specificity of $100 \%$ for HAEC [75] \\ - A cut-off of $\geq 4$ points has a reported sensitivity of $84 \%$ and specificity of $98 \%$ for HAEC [75] \\ In suspected HAEC, there should be a low threshold for hospital admission \\ - In mild symptoms with no fluid or electrolyte balance disturbance and normal inflammatory markers, \\ outpatient treatment with oral hydration $+/$ - oral metronidazole and rectal irrigations may be \\ appropriate, but prompt admission is indicated if symptoms do not improve. Recovery should be \\ followed up. \\ - Admit all other cases for in-patient monitoring and treatment \\ - Young age ( $<1$ year) lowers the threshold for admission
}

Following admission to hospital, patients with HAEC should be treated with intravenous fluid resuscitation, intravenous broad-spectrum antibiotics and rectal washouts.

- Saline rectal washouts to decompress the bowel should be performed 2-3 times per day until the patient is well enough for discharge

- Antibiotics may be changed to oral metronidazole once sufficient clinical improvement occurs

- Vital functions, fluid and electrolyte balance, including urine output, should be closely monitored.

- Abdominal plain film $\mathrm{x}$-ray should be considered

- Consulting the colorectal surgical team responsible for the patient's care is recommended

- Consult intensive care unit as appropriate

Intersphincteric botulinum toxin injections are recommended for patients with recurrent or persistent symptoms of outlet obstruction and/or HAEC

- In reports, 62-89\% of HSCR patients with HAEC and/or outlet obstruction improved after the

first botulinum toxin injection [82-86]

- Injections may need to be repeated 3-6 monthly

- The tendency to HAEC reduces over time; most episodes usually occur within the first few years after pull through

Principles of botulinum toxin administration

- Botox should be injected under a short general anaesthesia

- The patient is positioned in lateral decubitus or lithotomy position

- Injections are given in the four quadrants at the level of the dentate line into the anal sphincter musculature

- Exposure of the dentate line with retractors, and/or ultrasound guidance can facilitate correct localization of the injections

Prophylactic antibiotics may be considered for patients with frequently recurring or persistent HAEC

- Antibiotics may be effective treatment of HAEC in individual patients, but it has not been shown that prophylactic antibiotics prevent recurrent HAEC.

- Recurrent courses of antibiotics interfere with the long-term composition of the gut microbiota, and therefore rationalized use based on severity of symptoms is indicated

\section{At present, there is insufficient evidence to support recommending the routine use of} probiotics for the prevention of HAEC

- Although intestinal dysbiosis has been shown to be of importance in the aetiology of HAEC,

there are only two randomized controlled studies of probiotics and HAEC in the literature showing conflicting results.

In children with recurrent HAEC, consultation with a gastroenterologist and endoscopy should be considered

- Patients with HSCR have an increased risk of developing inflammatory bowel disease

- Fecal calprotectin is a non-invasive measure of intestinal inflammation in acute and chronic enterocolitis
Level of evidence III

Strength of recommendation: Strong, for

Level of agreement: 100\%

Level of evidence III

Strength of recommendation: Strong, for

Level of agreement: 100\%

Level of evidence III

Strength of recommendation: Strong, for Level of agreement: 100\%

Level of evidence III

Strength of recommendation: Conditional, for Level of agreement: 100\%
Level of evidence III

Strength of recommendation: Conditional, for Level of agreement: $100 \%$

Level of evidence I-III

Strength of recommendation: Conditional, against Level of agreement: 100\%

Level of evidence III

Strength of recommendation: Conditional, for

Level of agreement: 100\% 
Table 8 Pastor et al. (2009) HAEC score items [76]

\begin{tabular}{ll}
\hline History & 2 \\
Diarrhea with explosive stool & 2 \\
Diarrhea with foul-smelling stool & 1 \\
Diarrhea with bloody stool & 1 \\
Previous history of enterocolitis & 2 \\
Physical examination & 2 \\
Explosive discharge of gas and stool on rectal examination & 1 \\
Distended abdomen & 1 \\
Decreased peripheral perfusion & 1 \\
Lethargy & 1 \\
Fever & 1 \\
Radiologic examination & 1 \\
Multiple air fluid levels & 1 \\
Dilated loops of bowel & 1 \\
Sawtooth appearance with irregular mucosal lining & 1 \\
Cut off sign in rectosigmoid region with absence of distal air & 1 \\
Pneumatosis & 1 \\
Laboratory & \\
Leukocytosis & \\
Shift to left & \\
\hline
\end{tabular}

Note: Using a cut-off of $>4$ points to identify suspected HAEC is more sensitive and may have better clinical applicability than Pastor and co-workers' original cut-off of $\geq 10$ points [75]

injection [81, 83-86]. The number of hospitalizations for obstructive symptoms, particularly enterocolitis, are reduced by botulinum injection treatment [84]. Botulinum toxin injections may need to be repeated after 3-6 months, as the effects decrease over time. In rectosigmoid HSCR, the tendency to HAEC reduces over time, and most episodes occur during the first few years after pullthrough surgery [23].

Although the etiology of HAEC is not fully known, intestinal dysbiosis may be an important factor [87]. The gut microbiota composition of patients with HSCR may be significantly altered compared to healthy controls. Dysbiosis in HSCR has been characterized by a lack of microbial richness, and pathologic expansions of certain taxa, particularly Enterobacteria and Bacilli [87-90], and an altered Candida community [87]. Although antibiotics may be effective for treating HAEC in individual patients, it has not been shown that prophylactic antibiotics reduce the incidence of recurrent HAEC. This is likely to relate to the multifactorial etiology of HAEC in HSCR, which often includes concurrent obstruction. As recurrent courses of antibiotics may also interfere with the long-term composition of the gut microbiota [90], rationalized use based on the severity of symptoms is indicated.
It has been hypothesized that the prophylactic administration of probiotics after pull-through might decrease the incidence of HAEC. However, the only two randomized controlled trials to date have shown conflicting results. In one, no risk reduction was suggested [91], but the second suggested that probiotics significantly decreased the incidence of HAEC [92]. A recent systematic review and meta-analysis included three additional studies that could not show that probiotics prevent HAEC [93]. On this basis, there is currently insufficient evidence to recommend the routine use of probiotics for the prevention of HAEC. Recent studies have showed that patients with HSCR have an approximately 5 -fold increased risk of developing inflammatory bowel disease compared to the general population [94]. Endoscopic surveillance should be considered if inflammatory bowel disease is suspected, particularly if faecal calprotectin is continuously elevated.

\section{Management of patients with poor outcomes (Table 9)}

Although surgery is effective in most cases and techniques have improved over recent years, a small proportion of patients still experience poor functional outcomes $[28,95,96]$. These can be grossly divided into faecal incontinence and obstructive symptoms, including severe constipation. In children with normal intellectual development, In children with normal intellectual development, if adequate social continence for stool has not been achieved by the age of 4 after properly conducted surgery, further evaluation is advisable [97, 98]. Management protocols should not only aim for functional improvement, but also regard the prevention of the psycho-social consequences of fecal incontinence as an important goal [72].

The initial evaluation comprises a full survey of the stooling pattern, dietary history, growth and development. Examination of the integrity of the dentate line and sphincter muscles should be performed, preferably under general anaesthesia. This may be complemented by anorectal manometry or endorectal ultrasound $[44,99]$. In faecal incontinence, contrast enemas are helpful in differentiating between hypo- and hypermotile colon. Both hypomotility and outlet obstruction may lead to overflow incontinence and colonic dilatation, and should be differentiated from hypermotility disorders because their treatment is different. In patients with an intact dentate line and good sphincter function without outlet obstruction but colonic hypomotility, first line management comprises oral laxatives, supplemented with a short course of enemas if required. These aim to ensure complete colonic emptying to prevent faecal incontinence and soiling due to overflow. Patients with an intact dentate line and good sphincters but colonic hypermotility, most commonly due to loss of rectal reservoir, need interventions to 
Table 9 Recommendations for management of patients with poor functional outcomes

Children with normal intellectual development who are not continent of stool by 4 years of age should be considered for further evaluation. This should include:

- A stooling history and stooling pattern to evaluate for tendency to constipation or diarrhoea

(for treatment, see below), and involuntary passage of flatus.

- Dietary history and growth

- Examination under anaesthesia +/- anorectal manometry to assess the integrity of the anal canal, sphincter complex and dentate line, and for the presence of rolled muscle cuff, stricture or rectal spur

- Contrast enema to evaluate whether there is colonic dilatation, rectal spur, constipation or a twisted pull-through

- +/- Endorectal ultrasound to assess for sphincter defects

The management of fecal incontinence should aim for age-appropriate continence in children with normal intellectual development

- Primary prevention of the social consequences of fecal incontinence is a key goal of treatment

- Enabling normal social integration, school attendance and ability to participate in recreational

activities from the outset is important for self-esteem, friendships and long-term quality of life

- Deficient fecal continence in a child is also a source of stress for caregivers and psychological

support should be available for patients and families

- Cognitive impairment is associated with delays in achieving voluntary bowel control

Patients with an intact anal canal and appropriate pull-through but fecal incontinence should receive medical management as the first-line treatment

- For patients with a dilated colon and constipation (hypomotility), oral laxatives $+/-$ a short course of enemas to ensure regular and complete colonic emptying

- For patients without colonic dilatation and a tendency to loose stools (hypermotility), a constipating

diet + /- loperamide + /- bulking agents (pectin, psyllium)

- Measure fecal calprotectin, consider ileo-colonoscopy and repeat rectal biopsy

- Proceed to bowel management if there is failure to respond, despite adequate dosing and compliance

Patients with fecal incontinence and damaged anal canal should receive bowel management

- Maintaining an intact anal canal is a central goal in all standard operations for HSCR, and an indication

for performing pull-through surgery in specialist units

- An enterostomy is an option if bowel management fails to control symptoms

Children with persistent obstructive symptoms following pull-through surgery should undergo further evaluation and treatment:

- Rectal examination and contrast enema to rule out a mechanical cause and to assess for colonic dilatation

- If no mechanical cause is found, a trial of intersphincteric botulinum toxin injections

- Review the histology of the proximal margins of the originally resected bowel

- Repeat rectal biopsies to ensure normal innervation of the pulled-through bowel

- If repeated botulinum toxin injections are ineffective, histology is normal and there is no mechanical cause, bowel management can be offered

- Consider re-do surgery in patients with a recalcitrant stricture, twisted pull-through, rolled muscle cuff (Soave), rectal spur (Duhamel) or transition zone pull-through

Bowel management programme should comprise individualized care based on the symptom profile, local recommendations and values/preferences of the patient/carer(s)

- The goal of bowel management is to achieve regular and complete colonic emptying at predictable intervals

- Options include regular retrograde enemas or antegrade colonic irrigation via an antegrade

continence enema appendicostomy (ACE) or cecostomy +/- dietary modifications +/- laxatives

- Psychological support can assist patients and families in coping with symptoms

- An enterostomy may be required in isolated cases for intractable symptoms

\section{Level of evidence III}

Strength of recommendation: Strong, for

Level of agreement: $100 \%$

Level of evidence III

Strength of recommendation: Strong, for Level of agreement: 100\%

Level of evidence III

Strength of recommendation: Conditional, for Level of agreement: 100\%

Level of evidence III

Strength of recommendation: Conditional, for Level of agreement: 100\%

Level of evidence III

Strength of recommendation: Strong, for

Level of agreement: 100\%

Level of evidence III

Strength of recommendation: Conditional, for Level of agreement: 100\% slow down colonic transit. These include a constipating diet, loperamide and bulking agents (e.g. pectin, psyllium). If the dentate line and/or sphincter musculature are significantly damaged, bowel management to empty the colon by artificial means will be necessary to achieve social continence (see below) [100]. If both medical management and bowel management fail, a permanent stoma may be the last resort.

Several mechanical factors can lead to postoperative obstructive symptoms. These include an anastomotic stricture, Duhamel spur, obstructed Soave muscular cuff, twisted pull-through or retained aganglionotic or transition zone pull-through. Obstructive symptoms can occur with or without HAEC. Following a thorough clinical, dietary and stooling history as for fecal incontinence, rectal examination and contrast enema should be performed [101-105]. Histology should be reviewed, particularly with regard to the adequacy of the proximal resection margins of the pull-through $[55,101]$. Repeating transanal colonic biopsies should be considered to confirm normal innervation of the pulled through colon. For anastomotic strictures, a gentle course of anal dilatations may be attempted, with a low threshold for general anaesthesia if poorly tolerated. If no mechanical cause is 
found, first-line treatment is intersphincteric botulinum toxin injections to relieve internal sphincter achalasia. If symptoms fail to improve after repeated ( $>3$ ) botulinum toxin injections, bowel management is the second-line choice of treatment.

Bowel management comprises individualized management based on the patient's preferences. Options include regular retrograde enemas, or antegrade colonic irrigation via an antegrade continence enema appendicostomy (ACE) or cecostomy (CHAIT, button) in conjunction with oral laxatives and dietary modifications. Re-do surgery should be considered in symptomatic patients with a recalcitrant stricture, twisted pull-through, rolled muscle cuff (Soave), rectal spur (Duhamel), or aganglionic/transition zone pullthrough. The full evaluation and re-do surgical procedure should be performed in a centre with experience of complex pathology in HSCR and re-do procedures. Although redo-surgery is appropriate in selected cases resolves obstructing symptoms, it may be associated with relatively high rates of fecal incontinence and thus, careful patient selection is important $[103,105]$.

\section{Recommendations for genetic screening (Table 10)}

Most cases of HSCR that occur without an associated genetic syndrome or chromosomal anomaly are sporadic. The main gene in non-syndromic HSCR is the proto-oncogene RET. Coding mutations, which usually cause a loss of function in RET are present in approximately $15-35 \%$ of sporadic cases [106114]. In patients with a family history of HSCR, the occurrence of RET coding mutations is much higher, up to $50 \%[108,109,111]$. The second most commonly mutated gene in non-syndromic HSCR is EDNRB (endothelin receptor-beta) which is affected in $\sim 5 \%$ of cases [112]. Besides RET and EDNRB, many other genes have been implicated in HSCR, but the chances of detecting a mutation in these genes are very low. Although most HSCR is found in isolation it also is seen in the context of several syndromes, including Down syndrome (Trisomy 21), which is the most common, Shah-Waardenburg syndrome, Congenital Central Hypoventilation syndrome (CCHS), Mowat-Wilson syndrome, and GoldbergShprintzen syndrome.

Although most mutations in RET are inactivating, activating RET mutations are present in approximately $2-3 \%$ of all sporadic HSCR cases [113]. These mutations can cause multiple endocrine neoplasia type $2 \mathrm{~A}$ (MEN2A), a cancer syndrome characterized by medullary thyroid carcinoma, phaeochromocytoma of the adrenal glands, and hyperplasia of the parathyroid glands [114, 115]. In non-syndromic HSCR, referral for genetic testing of RET to exclude the rare possibility of a MEN 2A associated RET mutation that is also associated with an elevated risk for MTC should therefore be considered [113]. Molecular testing outcomes may also give a more accurate estimation for the parents of a HSCR patient of the risk of recurrence in future pregnancies. As many RET mutations prove to be sporadic and have not been inherited from the parents, screening is preferably performed in a TRIO setting that involves testing the father, mother and child. In suspected syndromic HSCR, patients should be screened for the gene that is associated with that specific phenotype.

\section{Evidence gaps and targets for further research}

There remain many caveats in the knowledge of Hirschsprung's disease. There are currently no practical capabilities for the prenatal diagnosis of HSCR, as abnormal sonographic findings are absent in the majority of fetuses with HSCR [116]. The definitions, causes and predisposing factors for HAEC and bowel dysmotility in the remaining ganglionic bowel remain incompletely understood. The composition intestinal microbiota and gut mucosal immunity in the pathogenesis of HAEC is a topic of current research interest. With regard to operative management, more comparative studies of the predominant pull-through techniques (Duhamel

Table 10 Recommendations for genetic screening of patients with HSCR

\footnotetext{
In non-syndromic HSCR, genetic testing of RET should be considered

- RET remains the major gene in HSCR

- Molecular testing allows a more accurate estimation of the risk of recurrence

- Genetic testing of RET allows exclusion of the rare possibility of MEN 2A-

associated RET mutation that is associated with an increased risk of medullary

thyroid cancer

- Parents or patients who wish to have genetic screening should be offered

referral for genetic consultation

- Genetic consultation is also recommended for patients with a family history of HSCR, where the incidence of RET mutations is even higher
}

In syndromic HSCR, patients should be offered referral for genetic consultation and screening for the specific gene associated with the syndromic phenotype
Level of evidence II-III

Strength of recommendation: Conditional, for Level of agreement: $100 \%$
Level of evidence III

Strength of recommendation: Conditional, for Level of agreement: $100 \%$ 
and ERP) are needed to gather higher quality evidence of the long-term outcomes, and whether laparoscopyassisted techniques confer advantages. Little is also known about the sexual function and fertility after pull-through surgery, although physical sexual functions appear to be preserved in the majority [117]. However, it has been shown that technically comparable low pelvic surgery for other pediatric bowel problems, impacts on later fertility, especially in females [118]. Further prospective research and multicenter studies are needed to obtain a full understanding of the long-term implications of HSCR on patients' health.

\section{Conclusions}

In rare or low-prevalence diseases such as HSCR, there is limited availability of high-quality clinical evidence. However, patients born with these conditions continue to require highly specialized care from infancy up to adulthood. In this document, consensusbased guidelines that describe the preferred approach of ERNICA, an international panel of experts from 10 major European centres to the management of rectosigmoid HSCR are presented. ERNICA remains committed to upholding and improving care standards for patients with HSCR.

\section{Materials and methods}

\section{Membership of the guideline workgroup}

The workgroup comprised an international panel of experts in HSCR from specialist centres in 8 European countries (Denmark, France, Germany, Finland, Italy, Netherlands, Norway, Sweden and the United Kingdom). These included pediatric surgeons, histopathologists, gastroenterologists, microbiologists and geneticists from 10 ERNICA (ERN) member centres and 3 associated experts selected by ERNICA. Patient representatives from SoMA, the German patient support organisation for anorectal malformations and HSCR and A.Mor.Hi, the Italian Society for HSCR, participated throughout the process.

Accreditation as an ERN centre requires demonstration and approval of specific specialist competencies and compliance with a comprehensive set of operational criteria [119]. These include demonstration of quality in organizational infrastructure, patient-centered management, clinical governance, sufficient care volumes, ability to report outcomes and commitment to upholding expertise through research, training and education. Recognition of competencies and membership is based on regular internal and external assessment.

\section{Background preparation}

A literature search was conducted using PubMed of articles published on HSCR from 1990 to 2018, and their references to identify articles that had not been brought up by the original search. Where studies of HSCR or pediatric populations were scarce or unavailable, data was derived from relevant studies from adult populations. Within groups, expert clinicians selected those publications they considered most relevant and highest quality for the reference pool of the guideline. Patient representatives contributed publications that best reflected their values to the workgroup. All authors had access to the reference pool during development. Articles were assigned an evidence level of I-III based on the Canadian Task Force on the Periodic Health Examination classification system (1979) summarized in Table 11 [120], with the expectation that in rare or low prevalence diseases most would fall into category III (descriptive studies, expert opinion).

\section{Determination of the core recommendation statements}

The working group met on three occasions: 1) to discuss the content of the guideline, 2) to decide on the core recommendations and supporting statements, and 3) to finalize the content, including voting on levels of agreement. After drafting recommendations, the supporting text and summary of the evidence was prepared. The AGREE II framework was used to assess the scope and rigour of the methodology [121]. The GRADE approach was used to rate the strength of the recommendations [122, 123]. Updating of the recommendations at 5 -year intervals by ERNICA was planned.

\section{Assigning strength of the recommendations}

Recommendations were classed as strong (for or against), if the workgroup felt highly confident of the balance between desirable and undesirable consequences [122, 123]. Recommendations were classed as conditional (for or against), if the appropriate course of action was considered subject to patient values and preferences, availability of resources and/or setting of the intervention $[122,123]$.

\section{Voting on levels of agreement}

Voting on levels of agreement was conducted at the final meeting. Recommendations receiving $<100 \%$ agreement were further discussed, revised and voted on again at the meeting until consensus was reached; $>75 \%$ agreement was considered necessary to finalize recommendations [124].

Table 11 Grading of levels of Evidence [120]

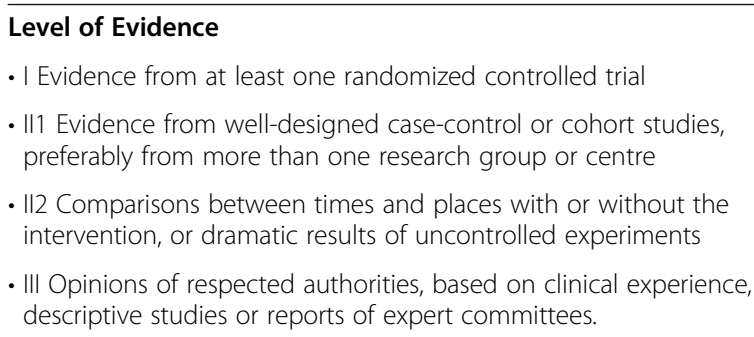




\section{Abbreviations}

ACE: Antegrade continence enema; AChE: Acetylcholine esterase; EDNRB: Endotheln receptor beta; ERN: European Reference Network; ERNICA: The European Reference Network for for rare inherited and congenital digestive disorders; ERAS: Enhanced recovery after surgery; ERP: Endorectal pull-through; EU: European Union; HSCR: Hirschsprung's disease; H\&E: Haematoxylin and eosin; MEN: Multiple endocrine neoplasia; MTC: Medullary thyroid cancer; RET: Rearranged during transfection protooncogene

\section{Acknowledgments}

We would like to thank Prof. Dr. René Wijnen, Renée de Ruiter and Olivia Spivack from ERNICA for organising the Network's meetings, that also enabled completion of this project.

\section{Authors' contributions}

All authors of the work have made substantial contributions to the conception and design of the work and to the literature search and its analysis. All authors have been involved in drafting the work and revising it critically for important intellectual content, and all authors read and approved the final manuscript.

\section{Funding}

Workgroup meetings and article-processing charges for open access publication in Orphanet Journal of Rare Diseases were supported by ERNICA European Reference Network. The authors have no other sources of funding to disclose.

\section{Availability of data and materials}

Not applicable to article type.

\section{Ethics approval and consent to participate}

Not applicable to article type.

\section{Consent for publication}

Not applicable to article type.

\section{Competing interests}

The authors declare that they have no competing interests

\section{Author details}

'Department of Pediatric Surgery, Children's Hospital, University of Helsinki and Helsinki University Hospital, Helsinki, Finland. ${ }^{2}$ Department of Pediatric Surgery, Erasmus MC - Sophia Children's Hospital, Rotterdam, The Netherlands. ${ }^{3}$ Department of Surgery, Division of Pediatric Surgery, Radboudumc-Amalia Children's Hospital, Nijmegen, The Netherlands. ${ }^{4}$ Department of Pediatric Surgery, Oslo University Hospital and University of Oslo, Oslo, Norway. ${ }^{5}$ Department of Pediatric Surgery and Pediatric Urology, University Hospital Frankfurt, Frankfurt/M, Germany. ${ }^{6}$ Department of Biology, University of Florence, A.Mor.Hi, The Italian Association for Hirschsprung's disease, Florence, Italy. 'Pathology Unit, Bambino Gesù Children's Hospital, IRCSS, Rome, Italy. ${ }^{8}$ Neonatal Surgery Unit - Department of Medical and Surgical Neonatology, Bambino Gesù Children's Hospital, IRCSS, Rome, Italy. ${ }^{9} \mathrm{SoMA}$, The German patient support organization for anorectal malformations and Hirschsprung Disease, Munich, Germany. ${ }^{10}$ Pediatric Surgery, Department of Women's and Children's Health, University Hospital of Padua, Padua, Italy. ${ }^{11}$ UCL Great Ormond Street Institute of Child Health; Department of Pediatric Gastroenterology, Great Ormond Street Hospital for Children, London, UK. ${ }^{12}$ Department of Surgery and Transplantation, Abdominal Centre, Rigshospitalet, Copenhagen, Denmark. ${ }^{13}$ Department of Pediatric Pathology, Hôpital Universitaire Robert Debré, Paris Diderot University, Paris, France. ${ }^{14}$ Department of Pediatric Gastroenterology, Hôpital Universitaire Robert Debré, Assistance Publique Hôpitaux de Paris, Université de Paris, Paris, France. ${ }^{15}$ Department of Pediatric Surgery, University Hospital Necker-Enfants Malades, APHP centre, Paris University, Paris, France. ${ }^{16}$ Department of Clinical Genetics, Erasmus Medical Center, Rotterdam, The Netherlands. ${ }^{17}$ Department of Pediatric Surgery, Karolinska University Hospital, Stockholm, Sweden.
Received: 7 October 2019 Accepted: 18 March 2020

Published online: 25 June 2020

\section{References}

1. $\quad$ Langer JC. Hirschsprung disease. Curr Opin Pediatr. 2013;25:368-74.

2. Neuvonen Ml, Kyrklund $\mathrm{K}$, Lindahl $\mathrm{HG}$, et al. A population-based, complete follow-up of 146 consecutive patients after transanal mucosectomy for Hirschsprung's disease. J Pediatr Surg. 2015;50:1653-8.

3. European Commission: European Reference Networks https://ec.europa.eu/ health/sites/health/files/ern/docs/2017_brochure_en.pdf, last Accessed 3rd October 2019

4. Bradnock TJ, Knight M, Kenny S, et al. on behalf of the British Association of Pediatric Surgeons Congenital Anomalies Surveillance System. Hirschprung's disease in the UK and Ireland: incidence and anomalies. Arch Dis Child. 2017;102:722-7.

5. Russell MB, Russell CA, Niebuhr E. An epidemiological study of Hirschsprung's disease. Acta Paediatr. 1994;83:68-71.

6. Duess JW, Hofmann AD, Puri P. Prevalence of Hirschsprung's disease in premature infants: a systematic review. Pediatr Surg Int. 2014;30:791-5.

7. Stensrud KJ, Emblem R, Bjornland K. Late diagnosis of Hirschsprung's disease - patient characteristics and results. J Pediatr Surg. 2012;47:1874-9.

8. Hernandez DG, Plesec T. Hirschsprung disease and use of calretinin in inadequate rectal suction biopsies. Arch Pathol Lab Med. 2013;137:1099102.

9. Knowles $\mathrm{CH}$, De Giorgio R, Kapur RP, et al. The London classification of gastrointestinal neuromuscular pathology: report on behalf of the Gastro 2009 International Working Group. Gut. 2010;59:882-7.

10. Schäppi MG, Staiano A, Milla PJ, et al. A practical guide for the diagnosis of primary enteric nervous system disorders. J Pediatr Gastroenterol Nutr. 2013; 57:677-86.

11. Jeong $H$, Jung $H R$, Hwang I, et al. Diagnostic accuracy of combined acetylcholinesterase histochemistry and calretinin immunohistochemistry of rectal biopsy specimens in Hirschsprung's disease. Int J Surg Pathol. 2018;26: 507-13.

12. Guinard-Samuel V, Bonnard A, De Lagausie $P$, et al. Calretinin immunohistochemistry: a simple and efficient tool to diagnose Hirschsprung disease. Mol Pathol. 2009;22:1379-84.

13. Moore SW, Johnson G. Acetylcholinesterase in Hirschsprung's disease. Pediatr Surg Int. 2005;21:255-63.

14. Janssen Lok M, Rassouil-Kirchmeier R, Köster N, et al. Development of nerve fiber diameter in young infants with Hirschsprung disease. J Pediatr Gastroenterol Nutr. 2018;66:253-6.

15. de Lorijn F, Kremer LCM, Reitsma JB, et al. Diagnostic tests in Hirschsprung disease: A systematic review. J Pediatr Gastroenterol Nutr. 2006;42:496-505.

16. Allen AR, Putnam AR, Presson AP, et al. The accuracy of suction rectal biopsy for the diagnosis of Hirschsprung's disease. Eur J Pediatr Surg. 2018. https://doi.org/10.1055/s-0038-1667040 [Epub ahead of print].

17. Schmiedeke E, de Blaauw I, Lacher M, et al. Towards the perfect ARM center: the European Union's criteria for centers of expertise and their implementation in the member states. A report from the ARM-Net. Pediatr Surg Int. 2015;31:741-5.

18. Pakarinen MP, Bjornland K, Qvist N, et al. Centralized pediatric surgery in the Nordic countries: A role model for Europe? Eur J Pediatr Surg. 2017;27:395-8.

19. Durkin N, Davenport M. Centralization of pediatric surgical procedures in the United Kingdom. Eur J Pediatr Surg. 2017;27:410-5.

20. Lampela H, Ritvanen A, Kosola S, et al. National centralization of biliary atresia care to an assigned multidisciplinary team provides high-quality outcomes. Scand J Gastroenterol. 2012;47:99-107.

21. Volanthen $R$, Lodge $P$, Barkun JS, et al. Toward a consensus on centralization in surgery. Ann Surg. 2018;268:712-4.

22. Ward ST, Dimick JB, Zhang W, et al. Association between hospital staffing models and failure to rescue. Ann Surg. 2018. https://doi.org/10.1097/SLA. 0000000000002744 [Epub ahead of print].

23. Neuvonen MI, Kyrklund K, Rintala RJ, et al. Bowel function and quality of life after transanal endorectal pull-through for Hirschsprung disease: controlled outcomes up to adulthood. Ann Surg. 2017;52:622-9.

24. Ralls MW, Freeman JJ, Rabah R, et al. Redo pullthrough for Hirschsprung disease: a single surgical group's experience. J Pediatr Surg. 2014;49:1394-9.

25. Dindo D, Demartines N, Clavien PA. Classification of surgical complications:a new proposal with evaluation in a cohort of 6336 patients and resultsof a survey. Ann Surg. 2004;240:205-13. 
26. Vallejo-Torres L, Melnychuk M, Vindrola-Padros C, et al. Discrete-choice experiment to analyse preferences for centralizing specialist cancer surgery services. Br J Surg. 2018;105:587-96

27. Wester T, Granström AL. Hirschsprung disease- bowel function beyond childhood. Semin Pediatr Surg. 2017;26:322-7.

28. Bjornland K, Pakarinen MP, Stenstrom $P$, et al. A Nordic multicenter survey of long-term bowel function after transanal endorectal pull-through in 200 patients with rectosigmoid Hirschsprung disease. J Pediatr Surg. 2017;52(9):1458-64.

29. Langer JC, Rollins MD, Levitt M, et al. Guidelines for the management of postoperative obstructive symptoms in children with Hirschsprung's disease. Pediatr Surg Int. 2017;33:523-6.

30. Hukkinen M, Koivusalo A, Rintala RJ, et al. Restorative proctocolectomy with J-pouch ileoanal anastomosis for total colonic aganglianosis among neonates and infants. J Pediatr Surg. 2014;49:570-4.

31. Zani A, Eaton S, Morini F, et al. European Pediatric Surgeons' Association survey on the management of Hirschsprung Disease. Eur J Pediatr Surg. 2017:27:96-101

32. Nelson RL, Gladman E, Barbateskovic M. Antimicrobial prophylaxis for colorectal surgery. Cochrane Database Syst Rev. 2014; 9: CD001181. doi: https:/doi.org/10. 1002/14651858.CD001181.pub4, last accessed 29th December 2018.

33. Rangel SJ, Islam S, St Peter SD, et al. Prevention of infectious complications after elective colorectal surgery in children: an American Pediatric Surgical Association outcomes and clinical trials committee comprehensive review. J Pediatr Surg. 2015;50:192-200.

34. Keckler SJ, Yang JC, Fraser JD, et al. Contemporary practice patterns in the surgical management of Hirschsprung's disease. J Pediatr Surg. 2009;44(6):1257-60.

35. Georgeson KE. Laparoscopic-assisted pull-through for Hirschsprung's disease. Semin Pediatr Surg. 2002;11(4):205-10.

36. Tomuschat C, Zimmer J, Puri P. Laparoscopic-assisted pull-through operation for Hirschsprung's disease: a systematic review and meta-analysis. Pediatr Surg Int. 2016;32(8):751-7

37. Antao B, Roberts J. Laparoscopic-assisted transanal endorectal coloanal anastomosis for Hirschsprung's disease. J Laparoendosc Adv Surg Tech A. 2005;15(1):75-9.

38. Nah SA, de Coppi P, Kiely EM, et al. Duhamel pull-through for Hirschsprung disease: a comparison of open and laparoscopic techniques. J Pediatr Surg. 2012;47(2):308-12.

39. Tannuri AC, Tannuri U, Romao RL. Transanal endorectal pull-through in children with Hirshsprung disease: Refinements and comparison of results with the Duhamel procedure. J Pediatr Surg. 2009:44:767-72.

40. El-Sawaf Ml, Drongowski RA, Chamberlain JN, et al. Are the long-term results of the transanal pull-through equal to those of the transabdominal pull-through? A comparison of the 2 approaches for Hirschsprung disease. J Pediatr Surg. 2007:42(1):41-7.

41. Minford JL, Ram A, Turnock RR, et al. Comparison of functional outcomes of Duhamel and transanal endorectal coloanal anastomosis for Hirschsprung's disease. J Pediatr Surg. 2004;39(2):161-5.

42. Mao YZ, Tang ST, Li S. Duhamel operation vs. transanal endorectal pullthrough procedure for Hirschsprung disease: A systematic review and metaanalysis. J Pediatr Surg. 2018;53(9):1710-5.

43. Seo S, Miyake H, Hock A, et al. Duhamel and Transanal Endorectal Pullthroughs for Hirschsprung' Disease: A Systematic Review and Meta-analysis. Eur J Pediatr Surg. 2018;28(1):81-8.

44. Stensrud KJ, Emblem R, Bjørnland K. Anal endosonography and bowel function in patients undergoing different types of endorectal pull-through procedures for Hirschsprung disease. J Pediatr Surg. 2015;50:1341-6.

45. Van Leeuwen K, Geiger JD, Barnett JL, et al. Stooling and manometric findings after primary pull-throughs in Hirschsprung's disease: Perineal versus abdominal approaches. J Pediatr Surg. 2002;37(9):1321-5.

46. Arts $E$, Botden SMB, Lacher $M$, et al. Duhamel versus transanal endorectal pull through (TERPT) for the surgical treatment of Hirschsprung's disease. Tech coloproctol. 2016;20:677-92

47. De la Torre L, Ortega A. Transanal versus open endorectal pull-through for Hirschsprung's disease. J Pediatr Surg. 2000;35:1630-2.

48. Nasr A, Langer JC. Evolution of the technique in the transanal pull-through for Hirschsprung's disease: effect on outcome. J Pediatr Surg. 2007;42(1):36-9.

49. Miyano G, Takeda M, Koga H, et al. Hirschsprung's disease in the laparoscopic transanal pull-through era: implications of age at surgery and technical aspects. Pediatr Surg Int. 2018;34(2):183-8.

50. Yang L, Tang ST, Cao GQ, et al. Transanal endorectal pull-through for Hirschsprung's disease using long cuff dissection and short V-shaped partially resected cuff anastomosis: early and late outcomes. Pediatr Surg Int. 2012;28(5):515-21.

51. Rintala RJ. Transanal coloanal pull-through with a short muscular cuff for classic Hirschsprung's disease. Eur J Pediatr Surg. 2003;13(3):181-6.

52. Levitt MA, Hamrick MC, Eradi B, et al. Transanal, full-thickness, Swenson-like approach for Hirschsprung disease. J Pediatr Surg. 2013;48(11):2289-95.

53. Elhalaby EA, Hashish A, Elbarbary MM, et al. Transanal one-stage endorectal pull-through for Hirschsprung's disease: a multicenter study. J Pediatr Surg. 2004;39(3):345-51 discussion -51.

54. Yamataka A, Kaneyama K, Fujiwara N, et al. Rectal mucosal dissection during transanal pull-through for Hirschsprung disease: the anorectal or the dentate line? J Pediatr Surg. 2009;44(1):266-9.

55. Lawal TA, Chatoorgoon K, Collins MH, et al. Redo pull-through in Hirschsprung's disease for obstructive symptoms due to residual aganglionosis and transition zone bowel. J Pediatr Surg. 2011;46(2):342-7.

56. Short HL, Heiss KF, Burch K, et al. Implementation of an enhanced recovery protocol in pediatric colorectal surgery. J Pediatr Surg. 2018;53:688-92.

57. Heiss KF, Raval MV. Patient engagement to enhance recovery for children undergoing surgery. Semin Pediatr Surg. 2018;27:86-91.

58. Wester T, Rintala RJ. Early outcome of transanal endorectal pull-through with a short muscle cuff during the neonatal period. J Pediatr Surg. 2004;39: 157-60.

59. Seo S, Miyake H, Hock A, et al. Duhamel and Transanal Endorectal Pullthroughs for Hirschsprung's Disease: Review and Meta-analysis. Eur J Pediatr Surg. 2018;28:81-8.

60. Aworanti $\mathrm{O}$, Hung J, McDowell D, et al. Are routine dilatations necessary post pull-through surgery for Hirschsprung disease? Eur J Pediatr Surg. 2013;23:383-8

61. Temple SJ, Shawyer A, Langer JC. Is daily dilatation by parents necessary after surgery for Hirschsprung disease and anorectal malformations? J Pediatr Surg. 2012;47:209-12

62. Kyrklund K, Neuvonen MI, Pakarinen MP, et al. Social morbidity in relation to bowel functional outcomes in anorectal malformations and Hirschsprung's disease. Eur J Pediatr Surg. 2018:28:522-8.

63. Meinds RJ, van der Steeg AFW, Sloots CEJ, et al. Long-term functional outcomes and quality of life in patients with Hirschsprung's disease. Br J Surg. 2019;106:499-507.

64. Witvliet MJ, van Gasteren S, van den Hondel D, et al. Predicting sexual problems in young adults with an anorectal malformation or Hirschsprung disease. J Pediatr Surg. 2018 Aug;53(8):1555-9.

65. Veras LV, Chotai PN, Tumen AZ, et al. Impaired growth outcomes in children with congenital colorectal diseases. J Surg Res. 2018 Sep;229:102-7.

66. Onishi S, Nakame K, Kaji T, et al. The bowel function and quality of life of Hirschsprung disease patients who have reached 18 years of age or older the long-term outcomes after undergoing the transabdominal soave procedure. J Pediatr Surg. 2017:52:2001-5.

67. Rintala RJ, Pakarinen MP. Long-term outocomes of Hirschsprung's disease. Semin Pediatr Surg. 2012;21:336-43.

68. Salamanca-Balen N, Seymour J, Caswell G, et al. The costs, resource use and cost-effectiveness of clinical nurse specialist-led interventions for patients with palliative care needs: A systematic review of international evidence. Palliat Med. 2018;32:447-65.

69. Nah SA, Ong CCP, Lie D, et al. Understanding experiences of youth growing up with anorectal malformation or Hirschsprung's disease to inform transition of care: A qualitative in-depth interview study. Eur J Pediatr Surg. 2018;28:67-74.

70. Cairo SB, Chiu PPL, Dasgupta R, et al. American Academy of Pediatrics Section on Surgery's Delivery of Surgical Care Committee. Transitions in care from pediatric to adult general surgery: Evaluating an unmet need for patients with anorectal malformation and Hirschsprung disease. J Pediatr Surg. 2018;53:1566-72

71. Hartman EE, Oort FJ, Sprangers MA, et al. Factors affecting quality of life of children and adolescents with anorectal malformations or Hirschsprung disease. J Pediatr Gastroenterol Nutr. 2008:47:463-71.

72. Hartman EE, Oort FJ, Aronson DC, et al. Quality of life and disease-specific functioning of patients with anorectal malformations or Hirschsprung's disease: a review. Arch Dis Child. 2011 Apr;96(4):398-406.

73. Wittmeier KDM, Hobbs-Murison K, Holland C, et al. Identifying information needs for Hirschsprung disease through caregiver involvement via social media: a prioritization study and literature review. J Med Internet Res. 2018; 20:e297. 
74. NICE guideline (NG43). (2016) Transition from childrens' to adults' services for young people using health or social care services. https://www.nice.org. uk/guidance/ng43, last accessed July 2019.

75. Frykman PK, Short S. Hirschsprung-associated enterocolitis: prevention and therapy. Semin Pediatr Surg. 2012;21:328-35.

76. Pastor AC, Osman F, Teitelbaum DH, et al. Development of a standardized definition for Hirschsprung-associated enterocolitis: a Delphi analysis. J Pediatr Surg. 2009;44:251-6.

77. Gosain A, Frykman PK, Cowles RA, et al. Guidelines for the diagnosis and management of Hirschsprung associated enterocolitis. Pediatr Surg Int. 2017;33:51721.

78. Langer JC, Rollins MD, Levitt M, et al. American Pediatric Surgical Association Hirschsprung Disease Interest Group. Guidelines for the management of postoperative obstructive symptoms in children with Hirschsprung disease. Pediatr Surg Int. 2017:33:523-6.

79. Gosain A, Brinkman AS. Hirschsprung's associated enterocolitis. Curr Opin Pediatr. 2015;27:364-49.

80. Halleran DR, Lu PL, Ahmad H, et al. Anal sphincter botulinum toxin injection in children with functional anorectal and colonic disorders: A large institutional study and review of the literature focusing on complications. J Pediatr Surg. 2019. https://doi.org/10.1016/j.jpedsurg.2019.03.020 [Epub ahead of print].

81. Han-Geurts IJM, Hendrix VC, de Baauw I, et al. Outcome after anal intrasphincteric botox injection in children with surgically treated Hirschsprung disease. J Pediatr Gastroenterol Nutr. 2014;59:604-7.

82. Louis-Borrione C, Faure A, Garnier S, et al. Neurostimulation-guided anal intrasphincteric botulinum toxin injection in children with Hirschsprung Disease. J Pediatr Gastroenterol Nutr. 2019:68:527-32.

83. Wester T, Granström AL. Botulinum toxin is efficient to treat obstructive symptoms in children with 77 Hirschsprung disease. Pediatr Surg Int. 2015;31:255-9.

84. Patrus B, Nasr LJC, et al. Intrasphincteric botulinum toxin decreases the rate of hospitalization for postoperative obstructive symptoms in children with Hirschsprung disease. J Pediatr Surg. 2011;46:184-7.

85. Chumpitazi BP, Nurko S. Defecation disorders in children after surgery for Hirschsprung disease. J Pediatr Gastroenterol Nutr. 2011;53:75-9.

86. Koivusalo Al, Pakarinen MP, Rintala RJ. Botox injection treatment for anal outlet obstruction in patients with internal anal sphincter achalasia and Hirschaprung disease. Pediatr Surg Int. 2009;25:873-6.

87. Frykman PK, Nordenskjöld A, Kawaguchi A, et al. Characterization of bacterial and fungal microbiome in children with Hirschsprung disease with and without a history of enterocolitis: A multicenter study. PLoS One. 2015; 10(4):e0124172.

88. Yan Z, Poroyko V, Gu S, et al. Characterization of the intestinal microbiome of Hirschsprung's disease with and without enterocolitis. Biochem Biophys Res Commun. 2014:445(2):269-74.

89. Li Y, Poroyoko V, Yan Z, et al. Characterization of intestinal microbiomes of Hirschsprung's disease patients with or without enterocolitis using illumina Mi-Seq High-Throughput Sequencing. PLoS One. 2016;11:e0162079.

90. Neuvonen MI, Korpela K, Kyrklund K, et al. Intestinal Microbiota in Hirschsprung Disease. J Pediatr Gastroenterol Nutr. 2018;67:594-600.

91. El-Sawaf M, Siddiqui S, Mahmoud M, et al. Probiotic prophylaxis after pullthrough for Hirschsprung disease to reduce incidence of enterocolitis: A prospective, randomized, double-blind, placebo-controlled, multicenter trial. J Pediatr Surg. 2013:48:111-7.

92. Wang X, Li Z, Xu Z, et al. Probiotics prevent Hirschsprung's diseaseassociated enterocolitis: a prospective multicenter randomized controlled trial. Int J Color Dis. 2015;30:105-10.

93. Nakamura H, Lim T, Puri P. Probiotics for the prevention of Hirschsprung-associated enterocolitis: a systematic review and meta-analysis. Pediatr Surg Int. 2018;34:189-93.

94. Granström AL, Amin L, Arnell H, et al. Increased risk of inflammatory bowel disease in a population-based cohort-study of patients with Hirschsprung disease. J Pediatr Gastroenterol Nutr. 2018:66:398-401.

95. Zimmer J, Tomuschat C, Puri P. Long-term results of transanal pull-through for Hirschsprung's disease: a meta-analysis. Pediatr Surg Int. 2016;32(8):7439. https://doi.org/10.1007/s00383-016-3908-z Epub 2016 Jul 6.

96. Granström AL, Danielson J, Husberg B, et al. Adult outcomes after surgery for Hirschsprung's disease: Evaluation of bowel function and quality of life. J Pediatr Surg. 2015;50(11):1865-9. https://doi.org/10.1016/j.jpedsurg.2015.06. 014 Epub 2015 Jun 24

97. Dasgupta R, Langer JC. Evaluation and management of persistent problems after surgery for Hirschsprung disease in a child. J Pediatr Gastroenterol Nutr. 2008;46:13-9.
98. Koppen IJ, von Gontard A, Chase J, et al. Management of functional nonretentive fecal incontinence in children: Recommendations from the International Children's Continence Society. J Pediatr Urol. 2016; 12:56-64.

99. Keshtgar AS, Ward HC, Clayden GS, et al. Investigations for incontinence and constipation after surgery for Hirschsprung's disease in children. Pediatr Surg Int. 2003;19(1-2):4-8 Epub 2002 Nov 14.

100. Bischoff A, Frischer J, Knod JL, et al. Damaged anal canal as a cause of fecal incontinence after surgical repair for Hirschsprungdisease - a preventable and under-reported complication. J Pediatr Surg. 2017;52(4):549-53.

101. Ralls MW, Coran AG, Teitelbaum DH. Reoperative surgery for Hirschsprung disease. Semin Pediatr Surg. 2012;21:354-63.

102. Dickie BH, Webb KM, Eradi B, et al. The problematic Soave cuff in Hirschsprung disease: manifestations and treatment. J Pediatr Surg. 2014;49(1):77-80.

103. Obermayr F, Hacker HW, Bornemann W, et al. Redo-endorectal pull through following various pull through procedures in Hirschsprung's disease. Langenbeck's Arch Surg. 2008;393:493-9.

104. Friedmacher F, Puri P. Residual aganglionosis after pull-through operation for Hirschsprung's disease: A systematic review and metaanalysis. Pediatr Surg Int. 2011;27:1053-7.

105. Dingemans AJM, van der Steeg HJJ, Rassouli-Kirchmeier R, et al. Redo pull-through surgery in Hirschsprung disease: Short-term clinical outcome. J Pediatr Surg. 2017;52:1446-50.

106. Edery P, Lyonnet S, Mulligan LM, et al. Mutations of the RET protooncogene in Hirschsprung's disease. Nature. 1994;367:378-80.

107. Romeo G, et al. 1994 Point mutations affecting the tyrosine kinase domain of the RET proto-oncogene in Hirschsprung's disease. Nature. 1994;367:377-8.

108. Hofstra RM, Wu Y, Stulp RP, et al. RET and GDNF gene scanning in Hirschsprung patients using two dual denaturing gel systems. Hum Mutat. 2000;15:418-29.

109. Attie T, Pelet A, Edery $P$, et al. Diversity of RET proto-oncogene mutations in familial and sporadic Hirschsprung disease. Hum Mol Genet. 1995;4:1381-6.

110. Pasini B, Borrello MG, Greco A, et al. Loss of function effect of RET mutations causing Hirschsprung disease. Nat Genet. 1995;10:35-40.

111. Virtanen VB, Pukkala E, Kivisaari R, et al. Thyroid cancer and cooccurring RET mutations in Hirschsprung's disease. Eur J Med Genet. 2018. https://doi.org/10.1016/j.ejmg.2018.07.019 [Epub ahead of print].

112. Amiel J, Sproat-Emison E, Garcia-Barcelo M, et al. Hirschsprung disease, associated syndromes and genetics: a review. J Med Genet. 2008;45:1-14.

113. Sijmons RH, Hofstra RM, Wijburg FA, et al. Oncological implications of RET gene mutations in Hirschsprung's disease. Gut. 1998;43:542-7.

114. Mulligan LM, Kwok JB, Healey CS, et al. Germ-line mutations of the RET proto-oncogene in multiple endocrine neoplasia type 2A. Nature. 1993;363:458-60.

115. Donis-Keller H, Dou S, Chi D, et al. Mutations in the RET proto-oncogene are associated with MEN 2A and FMTC. Hum Mol Genet. 1993;2:851-6.

116. Jakobson-Setton A, Weissmann-Brenner A, Achiron R, et al. Retrospective analysis of prenatal ultrasound of children with Hirschsprung disease. Prenat Diagn. 2015;35:699-702.

117. Neuvonen M, Kyrklund K, Taskinen S, et al. Lower urinary tract symptoms and sexual functions after endorectal pull-through for Hirschsprung disease: controlled long-term outcomes. J Pediatr Surg. 2017 Aug;52(8):1296-301.

118. Shannon A, Eng K, Kay M, et al. Long-term follow-up of ileal pouch anal anastomosis in a large cohort of pediatric and young adult patients with ulcerative colitis. J Pediatr Surg. 2016;51:1181-6.

119. European Commission: ERN assessment manual for applicants. 4Operational Criteria for the assessment of Healthcare Providers http://ec. europa.eu/research/participants/data/ref/other_eu_prog/hp/guide/pse/hpasses-manual-ern-op-criteria-hc-providers_en.pdf, last accessed 6th December 2018

120. Canadian Task Force on the Periodic Health Exmination: Task Force Report. CMA Journal 1979; 121: 1193-1254.

121. Brouwers M, Kho ME, Browman GP, et al. on behalf of the AGREE Next Steps Consortium. AGREE II: Advancing guideline development, reporting and evaluation in healthcare. Can Med Assoc J. 2010;182:E839-42. https:// doi.org/10.1503/cmaj.090449.

122. Andrews J, Guyatt G, Oxman AD, et al. GRADE guidelines: 14. Going from evidence to recommendations: the significance and presentation of recommendations. J Clin Epidemiol. 2013;66:719-25. 
123. Canadian Task Force on Preventitive Health Care. Putting prevention into practice. GRADE: Grades of Recommendation, Development, Assessment and Evaluation. https://canadiantaskforce.ca/wp-content/uploads/2016/05/ grade-en.pdf, last accessed 8th December 2018.

124. Forbes A, Escher J, Hebuterne X, et al. ESPEN guideline: Clinical nutrition and inflammatory bowel disease. Clin Nutr. 2017;36:321-47.

\section{Publisher's Note}

Springer Nature remains neutral with regard to jurisdictional claims in published maps and institutional affiliations.

Ready to submit your research? Choose BMC and benefit from:

- fast, convenient online submission

- thorough peer review by experienced researchers in your field

- rapid publication on acceptance

- support for research data, including large and complex data types

- gold Open Access which fosters wider collaboration and increased citations

- maximum visibility for your research: over $100 \mathrm{M}$ website views per year

At BMC, research is always in progress.

Learn more biomedcentral.com/submissions 